\title{
The Role of Usual Source of Care in Cholesterol Treatment
}

\author{
Paul Winters, MS, Daniel Tancredi, PhD, and Kevin Fiscella, MD, MPH
}

Background: A usual source of care (USOC) has been associated with improved preventive and chronic care, but its relationship with lipid management has not been well described. The objectives of this study were (1) to examine the association of USOC with statin use among persons meeting eligibility guidelines for treatment, and (2) to examine the association of USOC with low-density lipoprotein goal attainment among those receiving statins.

Methods: We examined statin use among adults aged 21 to 79 years who participated in the National Health and Nutrition Examination Survey, 1999 to 2006. We used criteria from the third Adult Treatment Panel about the treatment of high cholesterol to assess eligibility and the examined factors that predicted current use of statins. Among those currently taking statins, we assessed achievement of target low-density lipoprotein cholesterol based on the third Adult Treatment Panel's goals.

Results: Among the 12,979 participants, nearly $14 \%$ were eligible. Having a USOC was significantly associated with the use of statins among those who were eligible but not with goal attainment among those taking statins. Significant predictors of goal attainment were higher income and education and being in a more recent cohort.

Conclusion: In a national sample USOC was significantly associated with the use of statins among eligible adults but not with low-density lipoprotein cholesterol goal attainment for those using statins. (J Am Board Fam Med 2010;23:179-185.)

Keywords: Cholesterol, Usual Source of Care, Lipid, Statin, NHANES, Data Pooling

Having a usual source of care (USOC; eg, first contact) is a core feature of primary care and is embedded in the principles of the patient-centered medical home. ${ }^{1}$ Having a USOC has been associated with improved access to care, improved receipt of preventive care, ${ }^{2,3}$ weight loss among patients screened for hypertension or cholesterol, and improved communication, ${ }^{4}$ adherence, and health sta-

This article was externally peer reviewed.

Submitted 17 April 2009; revised 10 August 2009; accepted 17 August 2009.

From the Departments of Family Medicine and Community and Preventive Medicine, University of Rochester, New York (PW, KF); and the Department of Pediatrics, Center for Healthcare Policy and Research, University of California at Davis (DT).

Funding: The National Heart Lung and Blood Institute (1R01 HL081066-01A2).

Conflict of interest: none declared.

Corresponding author: Kevin Fiscella, MD, MPH, 1381 South Ave, Rochester, NY 14620 (E-mail: Kevin_ Fiscella@URMC.rochester.edu).

\footnotetext{
See Related Commentary on Page 149.
}

tus. ${ }^{5}$ When a USOC is combined with provider accessibility and well-organized care, key health care disparities are eliminated. ${ }^{6}$ Disruptions in USOC are associated with emergency department visits $^{7}$ and avoidable hospitalizations. ${ }^{8}$ USOC is also associated with better chronic care management and disease control for human immunodeficiency virus,

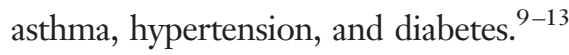

There are few data regarding the impact of continuity of care on cholesterol management beyond improvements in cholesterol screening. ${ }^{14,15}$ Using recent national data, we examined 2 questions: (1) Is continuity of care associated with appropriate treatment of high cholesterol with statins? and (2) Is continuity of care associated with attainment of low-density lipoprotein (LDL) goals among persons currently being treated with statins?

\section{Methods}

Study Sample

We used publicly available data from the $\mathrm{Na}$ tional Health and Nutrition Examination Survey (NHANES) conducted from 1999 to 2000, 2001 to 2002,2003 to 2004 , and 2005 to 2006 by 
the National Center for Health Statistics of the Centers for Disease Control and Prevention. NHANES is an ongoing survey designed to provide nationally representative estimates for the noninstitutionalized population of the United States based on a multistage, stratified sampling frame. ${ }^{16}$ Survey data include household interviews, examinations, and testing. After the interview, participants are invited to mobile examination centers. The protocol for each NHANES was approved by the National Center for Health Statistics of the Centers for Disease Control and Prevention Institutional Review Board. Informed consent was obtained from each participant.

Our sample was restricted to the 16,681 adults (older than 20 years) for whom criteria from the third Adult Treatment Panel (ATP III) were developed (ie, excluding those $\geq 80$ years of age). LDL cholesterol (LDL-C) values were available for 16,021 persons; of these, complete data for all study variables were available for $12,979(81.0 \%)$ participants, which corresponded to $84.4 \%$ of the target population (adjusted for population weights).

\section{Measures}

USOC was assessed by response to 2 questions: (1) Is there a place that you usually go when you are sick or you need advice about health? and (2) What kind of place do you go most often? We coded participants as having a USOC based on an affirmative response to the former question and their report of going to "a clinic or health center," "doctor's office or health maintenance organization," or a "hospital outpatient department." Sociodemographic factors included self-reported age, sex, race, ethnicity, socioeconomic status (percent of federal poverty level), and educational attainment. Risk factors for coronary heart disease (CHD) and morbidity included LDL, high-density lipoprotein (HDL), total cholesterol, blood pressure, history of $\mathrm{CHD}$, myocardial infarction, stroke, angina, diabetes, cigarette smoking, use of antihypertensive medication, and family history of CHD. Access factors included the language usually spoken at home (English or other), whether the participant had any health insurance or none, and the number of visits during the past year (intervals).

Participants were classified as having hypertension if, based on the average of 3 blood pressure measurements, they had a systolic blood pressure of $140 \mathrm{~mm} \mathrm{Hg}$ or more and/or diastolic blood pres- sure of $90 \mathrm{~mm} \mathrm{Hg}$ or more and/or they reported currently using antihypertensive medication. Medication use (including the use of statins) was based on a series of questions about any prescription drugs the participant reported having taken during the previous month. For each drug reported, the participant was asked to show the medication container to allow the interviewer to record the drug name. This information was used to ascertain participants' current use of any statin.

We estimated pretreatment total cholesterol, LDL-C, and HDL cholesterol based on the expected reduction associated with the specific lipid-lowering therapy the patient was using (based on inspection of the medication bottle). ${ }^{17,18}$ In sensitivity analyses we examined values $\pm 35 \%$ of the original estimated percent reduction. (The estimated percentage reduction for different lipid values associated with each lipid lowering drug are available on request.) Because LDL-C values were only available for a subsample, we imputed LDL-C values based on total cholesterol and HDL cholesterol using a predictive model developed using the subsample. The $r^{2}$ for LDL-C prediction was 0.90 and effect sizes for USOC (and other factors) were similar between the full sample and the subsample of participants for whom LDL-C values were obtained.

\section{Assessment for Statin Eligibility and Target LDL-C}

We applied the ATP III recommendations for the treatment of high cholesterol among adults (updated in 2004) to assess participant eligibility for statin use. $^{19,20}$ ATP III guidelines use variable LDL-C thresholds for treatment based on 3 categories of 10 -year risk for $\mathrm{CHD}(<10 \%, 10 \%$ to $20 \%$, and $>20 \%$ ). Patients with no CHD or CHD risk equivalents (diabetes, stroke, or peripheral vascular disease) were assessed for major CHD risk factors; CHD risk (cigarette smoking, hypertension, low HDL cholesterol $(<40 \mathrm{mg} / \mathrm{dL})$; family history of premature $\mathrm{CHD}$; and older age (men $\geq 45$ years and women $\geq 55$ years). HDL cholesterol $\geq 60 \mathrm{mg} / \mathrm{dL}$ was considered protective and resulted in a loss of the equivalent of a major CHD risk factor.

Patients with $\leq 1$ major CHD risk factor were considered to be in the lowest risk category with a 10 -year risk of $<10 \%$. Participants with $\geq 2$ risk factors underwent Framingham risk scoring to sort them into the same 3 risk-group categories. Participants with $\mathrm{CHD}$, CHD risk equivalents, or a Fra- 
mingham risk score $>20 \%$ were placed in the group at highest risk.

For adults with 0 to 1 risk factors, the statin eligibility threshold for elevated LDL-C was $\geq 190$ $\mathrm{mg} / \mathrm{dL}$, with a LDL-C goal of $<160 \mathrm{mg} / \mathrm{dL}$. For adults in the intermediate risk category $(2+$ risk factors), the goal was $130 \mathrm{mg} / \mathrm{dL}$. The statin threshold was $130 \mathrm{mg} / \mathrm{dL}$ for those with a 10 -year CHD risk of $10 \%$ to $20 \%$ and $160 \mathrm{mg} / \mathrm{dL}$ for those with a 10 -year CHD risk of $<10 \%$. For adults in the highest risk group, the statin threshold was $\geq 130 \mathrm{mg} / \mathrm{dL}$, with a goal of $\leq 100 \mathrm{mg} / \mathrm{dL}$. In the 2004 update an option was added for reducing the LDL-C to $<70 \mathrm{mg} / \mathrm{dL}$ for those in the highest risk group.

\section{Statistical Analyses}

The data were analyzed using SAS-Callable SUDAAN software version 10.0.0 (SAS Institute Inc., Research Triangle Park, NC); we incorporated the complex survey design specifications to yield appropriate standard errors and parameter estimates reflecting the noninstitutionalized, civilian US population. The dependent variable for the first logistic regression model was statin use among those eligible for statin therapy according to ATP III criteria and estimated pretreatment lipids. Social risk factors included age group $(<35$ years old, 35 to 44 years old, 45 to 54 years old, 55 to 64 years old, or $\geq 65$ years old); sex; race/ethnicity (white, black, Hispanic, or other); years of schooling $(<12$ years, 12 years, and $>12$ years); percent of Federal poverty level $(<100 \%, 100 \%$ to $199 \%, 200 \%$ to $299 \%, 300 \%$ to $499 \%$, and $\geq 500 \%$ ). Access factors included having a USOC, having insurance or having no insurance, and preferred language (English or other).

The dependent variable for the second set of logistic regression models was whether the LDL-C level was at goal and included only those respondents currently taking statins; the independent variables were the same as those in the first set of analyses. In both analyses, 2-way interactions among independent variables were explored. In this study we focused on social risk factors. We used 0.05 (or no overlap, with 1.0 for $95 \% \mathrm{CI}$ ) for tests of statistical significance.

\section{Results}

Of the 12,979 persons with complete data, 2,524 (19.4\%) reported no USOC. The characteristics of persons with a USOC compared with those without are shown in Table 1. Those without a USOC were younger, more likely men, more likely to be a race other than white, more likely to prefer a language other than English, poorer, less educated, more likely to be uninsured, have lower CHD risk, and less likely to be taking statins. Each of these differences was statistically significant $(P<.0001)$.

Among the 12,979 participants, 1,927 were potentially eligible for statin treatment. Among these, $25 \%$ were already taking statins. After controlling for patient sociodemographic characteristics and access, eligible participants who had a USOC were significantly more likely (odd ratio, 4.47; 95\% CI, 2.09-9.54) to be using statins (Table 2). Other predictors of statin use included age and participating in the survey during a later year (ie, statin use improved over time). These findings were robust to sensitivity analyses. We used a lower threshold for high-risk patients, eg, $<70 \mathrm{mg} / \mathrm{dL}$ of LDL-C. The results were similar among patients in subsamples for whom LDL-C were available or for whom ankle brachial blood pressure ratio was available and peripheral arterial disease $(<0.9)$ was included as a CHD risk equivalent. When we varied the estimated effect of cholesterol-lowering drugs on lipids by $\pm 35 \%$ (of the original effect), the effect of USOC ranged from 2.0 to 2.9 .

Among the 1333 participants who were appropriately treated with statins, there was a trend toward the association of USOC with the achievement of LDL-C goal (odds ratio, 2.0; 95\% CI, 0.94-4.6) that did not reach statistical significance. Significant predictors of failing to reach LDL-C goal included poverty and lower education, and participation in early years included being female, higher poverty level, and lower income (Table 3). Restriction of the sample to participants using statins who were presumed eligible or to those for whom LDL-C values were available yielded similar findings.

\section{Discussion}

In this nationally representative sample we found that having a USOC was associated with appropriate treatment with statins. We also found a nonstatistically significant trend for an association between USOC and the attainment of LDL-C goals among patients who were appropriately treated with statins. Interestingly, socioeconomic factors (ie, income and education) were not associated with 
Table 1. Characteristics of Adults in the National Health and Nutrition Examination Survey $(n=12,979) 1999$ to 2006 Sample by Usual Source of Care $^{21}$

\begin{tabular}{|c|c|c|c|c|}
\hline \multirow[b]{2}{*}{ Descriptive Variable } & \multirow[b]{2}{*}{ Total (\%) } & \multicolumn{2}{|c|}{$\begin{array}{l}\text { Percentage by Usual Source } \\
\text { of Care }\end{array}$} & \multirow[b]{2}{*}{$P$} \\
\hline & & No & Yes & \\
\hline Total & 100 & 17.9 & 82.1 & \\
\hline Age (years) & & & & $<.0001$ \\
\hline $21-34$ & 30.5 & 49.4 & 26.3 & \\
\hline $35-44$ & 24.4 & 23.7 & 24.5 & \\
\hline $45-54$ & 22.2 & 17.7 & 23.1 & \\
\hline $55-64$ & 12.2 & 6.2 & 13.5 & \\
\hline$>65$ & 10.9 & 3 & 12.6 & \\
\hline Male & 48 & 67.2 & 43.8 & $<.0001$ \\
\hline Race/ethnicity & & & & $<.0001$ \\
\hline Hispanic & 12.7 & 23.1 & 10.4 & \\
\hline White & 72.2 & 59.4 & 75 & \\
\hline Black & 10.3 & 11.2 & 10.1 & \\
\hline Other & 4.8 & 6.3 & 4.5 & \\
\hline Federal poverty level (\%) & & & & $<.0001$ \\
\hline$<100$ & 11.5 & 18.2 & 10 & \\
\hline 100-199 & 19.1 & 26.8 & 17.5 & \\
\hline 200-299 & 15.9 & 17.3 & 15.6 & \\
\hline $300-499$ & 26.8 & 21.6 & 28 & \\
\hline$>500$ & 26.6 & 16.1 & 29 & \\
\hline Education (years) & & & & $<.0001$ \\
\hline$<12$ & 17.1 & 26.4 & 15 & \\
\hline 12 & 25 & 26.7 & 24.6 & \\
\hline$>12$ & 57.9 & 46.8 & 60.3 & \\
\hline No insurance & 18.2 & 46.9 & 11.9 & $<.0001$ \\
\hline Physician visits & & & & $<.0001$ \\
\hline 0 & 17.2 & 46.7 & 10.8 & \\
\hline 1 & 21.6 & 25 & 20.8 & \\
\hline $2-3$ & 27.3 & 15.9 & 29.8 & \\
\hline $4-9$ & 21.6 & 7.8 & 24.6 & \\
\hline 10 to 12 & 5.5 & 1.8 & 6.3 & \\
\hline$\geq 13$ & 6.8 & 2.8 & 7.7 & \\
\hline Prefer English language & 90.6 & 81.2 & 92.7 & $<.00001$ \\
\hline CHD 10-year risk (\%) & & & & $<.00001$ \\
\hline$<10$ & 83.7 & 87.9 & 82.8 & \\
\hline $10-20$ & 15 & 11.4 & 15.7 & \\
\hline$>20$ & 1.3 & 0.7 & 1.5 & \\
\hline Taking statin & 5.35 & 0.9 & 6.3 & $<.0001$ \\
\hline
\end{tabular}

All results based on population weights.

CHD, coronary heart disease.

Centers for Disease Control and Prevention, National Center for Health Statistics. National Health and Nutrition Examination Survey Data. Available at http://www.cdc.gov/nchs/surveys.htm.

the use of statins but were associated with LDL-C goal attainment. Our findings are consistent with previous studies, which showed that having a USOC is associated with improved chronic disease management. $^{9-13}$
Our findings for goal attainment were consistent with previous data, showing that higher socioeconomic status is associated with improved quality of care, ${ }^{22-24}$ in part because of fewer cost barriers for people with a higher socioeconomic status. ${ }^{25}$ This 
Table 2. Use of Statins among Eligible Adults $(\mathbf{n}=$ 1927) in the National Health and Nutrition Examination Survey, 1999 to $2006^{21}$

\begin{tabular}{|c|c|}
\hline Predictor Variable & Odds Ratio (95\% CI) \\
\hline \multicolumn{2}{|l|}{ Survey year } \\
\hline 1999-2000 & $1.00(1.00-1.00)$ \\
\hline $2001-2002$ & $1.87(1.03-3.39)$ \\
\hline 2003-2004 & $5.63(3.54-8.95)$ \\
\hline 2005-2006 & $6.36(3.83-10.55)$ \\
\hline \multicolumn{2}{|l|}{ Usual source of care } \\
\hline No & $1.00(1.00-1.00)$ \\
\hline Yes & $4.64(2.14-10.04)$ \\
\hline \multicolumn{2}{|l|}{ Age (years) } \\
\hline $21-34$ & $1.00(1.00-1.00)$ \\
\hline $35-44$ & $14.80(3.25-67.41)$ \\
\hline $45-54$ & $21.42(4.91-93.29)$ \\
\hline $55-64$ & $28.67(6.73-122.12)$ \\
\hline$\geq 65$ & $35.86(8.24-156.15)$ \\
\hline \multicolumn{2}{|l|}{ Sex } \\
\hline Female & $1.00(1.00-1.00)$ \\
\hline Male & $0.87(0.67-1.12)$ \\
\hline \multicolumn{2}{|l|}{ Race/ethnicity } \\
\hline Hispanic & $0.81(0.42-1.55)$ \\
\hline Non-Hispanic white & $1.00(1.00-1.00)$ \\
\hline Non-Hispanic black & $0.93(0.64-1.34)$ \\
\hline Other & $1.15(0.58-2.30)$ \\
\hline \multicolumn{2}{|l|}{ Federal poverty level (\%) } \\
\hline$<100$ & $0.98(0.48-2.00)$ \\
\hline $100-199$ & $1.01(0.57-1.80)$ \\
\hline 200-299 & $0.99(0.60-1.64)$ \\
\hline $300-499$ & $0.97(0.58-1.60)$ \\
\hline$>500$ & $1.00(1.00-1.00)$ \\
\hline \multicolumn{2}{|l|}{ Education (years) } \\
\hline$>12$ & $0.77(0.45-1.30)$ \\
\hline 12 & $1.07(0.77-1.47)$ \\
\hline$<12$ & $1.00(1.00-1.00)$ \\
\hline \multicolumn{2}{|l|}{ Preferred language } \\
\hline English & $1.00(1.00-1.00)$ \\
\hline Other & $0.87(0.47-1.63)$ \\
\hline \multicolumn{2}{|c|}{ Health insurance coverage } \\
\hline No & $1.00(1.00-1.00)$ \\
\hline Yes & $1.98(0.96-4.12)$ \\
\hline
\end{tabular}

All results have been adjusted for insurance, language, usual source of care, and survey year.

Centers for Disease Control and Prevention, National Center for Health Statistics. National Health and Nutrition Examination Survey Data. Available at http://www.cdc.gov/nchs/ surveys.htm.

difference may reflect differences in the intensification of treatment by the provider or differences in patient adherence to that treatment and/or therapeutic lifestyle. ${ }^{26,27}$ Higher socioeconomic status
Table 3. Predictors of Low-Density Lipoprotein Cholesterol Goal Attainment among Adults ( $\mathrm{n}=$ 1,133) Taking Statins in the National Health and Nutrition Examination Survey, 1999 to $2006^{21}$

\begin{tabular}{|c|c|}
\hline Predictor Variable & Odds Ratio $(95 \% \mathrm{CI})$ \\
\hline \multicolumn{2}{|l|}{ Survey year } \\
\hline 1999-2000 & $1.00(1.00-1.00)$ \\
\hline 2001-2002 & $2.27(1.12-4.59)$ \\
\hline $2003-2004$ & $2.92(1.65-5.18)$ \\
\hline 2005-2006 & $3.81(2.07-6.99)$ \\
\hline \multicolumn{2}{|l|}{ Usual source of care } \\
\hline No & $2.04(0.91-4.54)$ \\
\hline Yes & $1.00(1.00-1.00)$ \\
\hline \multicolumn{2}{|l|}{ Age (years) } \\
\hline $21-34$ & $1.00(1.00-1.00)$ \\
\hline $35-44$ & $0.24(0.03-2.21)$ \\
\hline $45-54$ & $0.33(0.03-3.27)$ \\
\hline $55-64$ & $0.25(0.03-2.34)$ \\
\hline$\geq 65$ & $0.37(0.04-3.24)$ \\
\hline \multicolumn{2}{|l|}{ Sex } \\
\hline Female & $1.00(1.00-1.00)$ \\
\hline Male & $0.74(0.51-1.06)$ \\
\hline \multicolumn{2}{|l|}{ Race/ethnicity } \\
\hline Hispanic & $0.73(0.39-1.36)$ \\
\hline Non-Hispanic white & $1.00(1.00-1.00)$ \\
\hline Non-Hispanic black & $0.89(0.60-1.32)$ \\
\hline Other & $0.72(0.32-1.65)$ \\
\hline \multicolumn{2}{|l|}{ Federal poverty level (\%) } \\
\hline$<100$ & $0.42(0.22-0.80)$ \\
\hline $100-199$ & $0.59(0.37-0.93)$ \\
\hline $200-299$ & $1.00(1.00-1.00)$ \\
\hline $300-499$ & $0.87(0.52-1.45)$ \\
\hline$>500$ & $1.00(1.00-1.00)$ \\
\hline \multicolumn{2}{|l|}{ Education (years) } \\
\hline$<12$ & $0.59(0.41-0.86)$ \\
\hline 12 & $0.82(0.56-1.20)$ \\
\hline$>12$ & $1.00(1.00-1.00)$ \\
\hline \multicolumn{2}{|l|}{ Preferred language } \\
\hline English & $1.00(1.00-1.00)$ \\
\hline Other & $1.51(0.72-3.17)$ \\
\hline \multicolumn{2}{|c|}{ Health insurance coverage } \\
\hline No & $1.76(0.65-4.75)$ \\
\hline Yes & $1.00(1.00-1.00)$ \\
\hline
\end{tabular}

All results have been adjusted for insurance, language, usual source of care, and survey year.

Centers for Disease Control and Prevention, National Center for Health Statistics. National Health and Nutrition Examination Survey Data. Available at http://www.cdc.gov/nchs/ surveys.htm.

is associated with a healthy diet, physical activity, and higher rates of obesity. ${ }^{28,29}$ Each of these factors might contribute to lower goal attainment by 
socioeconomic status. Improvement in goal attainment over time has also been previously noted. ${ }^{30}$

Given the powerful effects of statins on cardiovascular and all-cause mortality, ${ }^{31,32}$ these results suggest that those lacking a USOC may be at higher risk. Specifically, less optimal management of high cholesterol among those without a USOC may contribute to higher long-term mortality.

Previous studies suggest that $>20 \%$ of the adult population lack a USOC, ${ }^{33}$ which is slightly higher than the $18 \%$ in this sample. Consistent with previous studies, ${ }^{33,34}$ we found that being uninsured, Hispanic, less educated, and poor were associated with no USOC. Among our sample nearly $50 \%$ of those without a USOC were uninsured and $45 \%$ had household incomes $200 \%$ of the poverty level.

In past studies, the most frequent reasons for lacking a USOC included lack of perceived need (ie, never/seldom sick) and cost associated with care. ${ }^{33}$ The reasons for lack of perceived need are unclear, but they may reflect lower illness burden and lack of perceived benefit from preventive care. Costs are a well-recognized barrier to insurance.

Having a USOC is often a prerequisite for initiating and continuing chronic disease management. This may be particularly true for cholesterol management. An emergency department or urgent care physician is unlikely to assess a person's need for statins or to start statin treatment. Similarly, patients who experience an interruption in USOC may no longer be able to obtain a prescription for their statin treatment.

Our findings are subject to several limitations. First, our measure of USOC did not distinguish between primary or specialty care or provider continuity. Provider continuity provides benefits beyond USOC alone..$^{2,35}$ It is conceivable that stronger effects might be observed with better measures. Second, our data are cross-sectional. We had no data about pretreatment cholesterol levels, drug doses, or the number of times that physicians intensified therapy. We estimated pretreatment lipid levels based on expected reductions in lipids with different lipid-lowering drugs. Nonetheless, our findings regarding the association of USOC with appropriate treatment with statins were robust in sensitivity analysis in which we varied the percent reduction in cholesterol with treatment. Given the relatively small subsample of participants for whom LDL-C was obtained, we imputed LDL-C based on total cholesterol and HDL cholesterol. Com- parison of effect sizes between the full sample and subsample showed similar results. The absence of an association between USOC and LDL-C was unexpected. This may reflect limitations of the measures discussed above as well as sample size limitations, but further research is needed to clarify this. Previous studies have noted that African Americans are less likely to receive statins or reach goal attainment. ${ }^{30,36,37}$ Whether these differences reflect diffusion of statin across groups over time or potential bias in imputation of pretreatment LDL-C levels cannot be determined from these data.

\section{Conclusion}

These national data show that USOC is associated with appropriate statin use. Lower income and education are associated with cholesterol goal attainment among those taking statins. These findings highlight the salience of USOC and socioeconomic factors in cholesterol treatment.

\section{References}

1. Kellerman R, Kirk L. Principles of the patient-centered medical home. Am Fam Phys 2007;76:774-5.

2. Blewett LA, Johnson PJ, Lee B, Scal PB. When a usual source of care and usual provider matter: adult prevention and screening services. J Gen Intern Med 2008;23:1354-60.

3. Doescher MP, Saver BG, Fiscella K, Franks P. Preventive care. J Gen Intern Med 2004;19:632-7.

4. DeVoe JE, Wallace LS, Pandhi N, Solotaroff R, Fryer GE Jr. Comprehending care in a medical home: a usual source of care and patient perceptions about healthcare communication. J Am Board Fam Med 2008;21:441-50.

5. Kieckhefer GM, Greek AA, Joesch JM, Kim H, Baydar N. Presence and characteristics of medical home and health services utilization among children with asthma. J Pediatr Health Care 2005;19:285-92.

6. Beal AC, Doty MM, Hernandez SE, Shea KK, Davis K. Closing the divide: how medical homes promote equity in health care: results from the Commonwealth Fund 2006 Health Care Quality Survey. Available at http://www.commonwealthfund.org/ Content/Publications/Fund-Reports/2007/Jun/ Closing-the-Divide-How-Medical-Homes-PromoteEquity - in - Health - Care - Results - From - The Commonwealth-F.aspx. Accessed 5 January 2010.

7. Weber EJ, Showstack JA, Hunt KA, Colby DC, Callaham ML. Does lack of a usual source of care or health insurance increase the likelihood of an emergency department visit? Results of a national population-based study. Ann Emerg Med 2005;45:4-12.

8. Gill JM, Mainous AG III. The role of provider 
continuity in preventing hospitalizations. Arch Fam Med 1998;7:352-7.

9. Goldstein RB, Rotheram-Borus MJ, Johnson MO, et al. Insurance coverage, usual source of care, and receipt of clinically indicated care for comorbid conditions among adults living with human immunodeficiency virus. Med Care 2005;43:401-10.

10. Halm EA, Wisnivesky JP, Leventhal H. Quality and access to care among a cohort of inner-city adults with asthma: who gets guideline concordant care? Chest 2005;128:1943-50.

11. Ahluwalia JS, McNagny SE, Rask KJ. Correlates of controlled hypertension in indigent, inner-city hypertensive patients. J Gen Intern Med 1997;12:7-14.

12. Moy E, Bartman BA, Weir MR. Access to hypertensive care. Effects of income, insurance, and source of care. Arch Intern Med 1995;155:1497-502.

13. Rhee MK, Cook CB, Dunbar VG, et al. Limited health care access impairs glycemic control in low income urban African Americans with type 2 diabetes. J Health Care Poor Underserved 2005;16:734-46.

14. Sambamoorthi U, McAlpine DD. Racial, ethnic, socioeconomic, and access disparities in the use of preventive services among women. Prev Med 2003;37:475-84.

15. Xu KT. Usual source of care in preventive service use: a regular doctor versus a regular site. Health Serv Res 2002;37:1509-29.

16. National Center for Health Statistics. The National Health and Nutrition Examination Survey (NHANES) analytic and reporting guidelines. Available at http://www.cdc.gov/nchs/data/nhanes/ nhanes_general_guidelines_june_04.pdf. Accessed 15 January 2010.

17. Law MR, Wald NJ, Rudnicka AR. Quantifying effect of statins on low density lipoprotein cholesterol, ischaemic heart disease, and stroke: systematic review and meta-analysis. BMJ 2003;326:1423.

18. Schulman KA, Kinosian B, Jacobson TA, et al. Reducing high blood cholesterol level with drugs. Costeffectiveness of pharmacologic management. JAMA 1990;264:3025-33.

19. Expert Panel on Detection, Evaluation, and Treatment of High Blood Cholesterol in Adults. Executive Summary of The Third Report of The National Cholesterol Education Program (NCEP) Expert Panel on Detection, Evaluation, and Treatment of High Blood Cholesterol in Adults (Adult Treatment Panel III). JAMA 2001;285:2486-97.

20. Grundy SM, Cleeman JI, Merz CN, et al. Implications of recent clinical trials for the National Cholesterol Education Program Adult Treatment Panel III guidelines. Circulation 2004;110:227-39.

21. Centers for Disease Control and Prevention, National Center for Health Statistics. National Health and Nutrition Examination Survey Data. Available at http://www.cdc.gov/nchs/surveys.htm. Accessed 20 January 2010.

22. Fiscella K, Franks P, Gold MR, Clancy CM. In- equality in quality: addressing socioeconomic, racial, and ethnic disparities in health care. JAMA 2000; 283:2579-84.

23. Asch SM, Kerr EA, Keesey J, et al. Who is at greatest risk for receiving poor-quality health care? N Engl J Med 2006;354:1147-56.

24. Rahimi AR, Spertus JA, Reid KJ, Bernheim SM, Krumholz HM. Financial barriers to health care and outcomes after acute myocardial infarction. JAMA 2007;297:1063-72.

25. Gellad WF, Haas JS, Safran DG. Race/ethnicity and nonadherence to prescription medications among seniors: results of a national study. J Gen Intern Med 2007;22:1572-8.

26. Avorn J, Monette J, Lacour A, et al. Persistence of use of lipid-lowering medications: a cross-national study. JAMA 1998;279:1458-62.

27. Goldberg KC, Melnyk SD, Simel DL. Overcoming inertia: improvement in achieving target low-density lipoprotein cholesterol. Am J Manag Care 2007;13:530-4.

28. Ervin RB. Healthy Eating Index scores among adults, 60 years of age and over, by sociodemographic and health characteristics: United States, 1999-2002. Adv Data 2008;(395):1-16.

29. Zhang Q, Wang Y. Trends in the association between obesity and socioeconomic status in US adults: 1971 to 2000. Obes Res 2004;12:1622-32.

30. Mann D, Reynolds K, Smith D, Muntner P. Trends in statin use and low-density lipoprotein cholesterol levels among US adults: impact of the 2001 National Cholesterol Education Program guidelines. Ann Pharmacother 2008;42:1208-15.

31. Baigent C, Keech A, Kearney PM, et al. Efficacy and safety of cholesterol-lowering treatment: prospective meta-analysis of data from 90,056 participants in 14 randomised trials of statins. Lancet 2005;366:1267-78.

32. Ridker PM, Danielson E, Fonseca FA, et al. Rosuvastatin to prevent vascular events in men and women with elevated C-reactive protein. N Engl J Med 2008;359:2195-207.

33. Viera AJ, Pathman DE, Garrett JM. Adults' lack of a usual source of care: a matter of preference? Ann Fam Med 2006;4:359-65.

34. Agency for Healthcare Research and Quality. 2007 National Healthcare Disparities Report. Available at http://www.ahrq.gov/qual/ndr08/nhdr08.pdf. Accessed 15 January 2010.

35. Ettner SL. The relationship between continuity of care and the health behaviors of patients: does having a usual physician make a difference? Med Care 1999;37:547-55.

36. Hyre AD, Muntner P, Menke A, Raggi P, He J. Trends in ATP-III-defined high blood cholesterol prevalence, awareness, treatment and control among US adults. Ann Epidemiol 2007;17:548-55.

37. Yood MU, McCarthy BD, Kempf J, et al. Racial differences in reaching target low-density lipoprotein goal among individuals treated with prescription statin therapy. Am Heart J 2006;152:777-84. 